\title{
Classification of hypertrophied hearts in essential hypertension: evaluation by left ventricular wall stress and adrenergic responses
}

\author{
YASURO SUGISHITA, KEIJI IIDA, KIMIHIKO YUKISADA, IWAO ITO \\ From the Cardiovascular Division, Department of Internal Medicine, Institute of Clinical Medicine, \\ University of Tsukuba, Ibaraki, Japan
}

SUMMARY Left ventricular mass, fractional shortening, and end systolic wall stress (mechanical 웅 indices) measured by echocardiography and the response of fractional shortening and end systolic wall stress to the infusion of isoproterenol $(0.02 \mu \mathrm{g} / \mathrm{kg} / \mathrm{min}$ for $5 \mathrm{~min}$ ) (a non-mechanical index) $\mathbb{\Phi}$ were studied in 57 patients (mean (SD) age 49(8)) with essential hypertension. Nineteen patients had subnormal end systolic wall stress (group 1), 25 patients had normal end systolic wall stress and $\stackrel{\rho}{=}$ slightly increased left ventricular mass (group $2 \mathrm{~A}$ ), and 13 patients had normal end systolic wall $\vec{\oplus}$ stress and considerably increased left ventricular mass (group 2B). Plasma noradrenaline $\stackrel{\infty}{\infty}$ concentration was higher in group $2 \mathrm{~B}$ than in the other groups. When end systolic wall stress was $>12 \mathrm{~g} / \mathrm{cm}^{2}$ this variable showed a significant inverse linear relation with fractional shortening before isoproterenol infusion. The inotropic response to isoproterenol was measured as the increase of fractional shortening corrected for the decrease of end systolic wall stress ( $\triangle$ fractional shortening $/-\triangle$ end systolic wall stress). The mean (SD) change in $\Delta$ fractional shortening $/-\triangle$ end systolic wall stress was significantly larger in group $1\left(1.40(0.60) \mathrm{cm}^{2} / \mathrm{g}\right)$ than in group $2 \mathrm{~A}(0.85$ $\left.(0.39) \mathrm{cm}^{2} / \mathrm{g}\right)$, and was significantly larger in group $2 A$ than in group $2 B\left(0.56(0.15) \mathrm{cm}^{2} / \mathrm{g}\right)$.

In patients with hypertensive hypertrophy with subnormal end systolic wall stress (inappropriate hypertrophy) the $\beta$ adrenergic response is increased; in hypertensive hypertrophy with normal end systolic wall stress (appropriate hypertrophy), however, it is normal, or becomes reduced as plasma noradrenaline increases.

When left ventricular pressure is excessive the left ventricle becomes hypertrophied in an attempt to reduce left ventricular systolic wall stress. The hypertrophy results in left ventricular dysfunction. The way that the grade of hypertension, the extent of hypertrophy, and the severity of left ventricular functional abnormalities interact has not been established.

Several investigators have shown that adrenergic factors can cause cardiac hypertrophy to develop in laboratory animals. ${ }^{2}$ These results remain

Requests for reprints to Dr Yasuro Sugishita, Cardiovascular Division, Department of Internal Medicine, Institute of Clinical Medicine, University of Tsukuba, Sakura-mura, Niihari-gun, Ibaraki 305, Japan.

Accepted for publication 8 June 1987 controversial and this effect has not been investigated in human hypertension.

We have attempted to classify clinical hypertensive $\stackrel{ }{=}$ hypertrophy on the basis of its mechanical (left $\frac{7}{0}$ ventricular systolic wall stress) and non-mechanical effects (adrenergic response).

\section{Patients and methods}

\section{PATIENTS}

We studied 57 hypertensive patients with left $\stackrel{\circ}{\circ}$ ventricular hypertrophy who had had hypertension for $>$ five years. We measured blood pressure by cuff sphygmomanometer, using phases 1 and 5 of the Korotkoff sounds. Arterial hypertension was defined $\overparen{\mathbb{D}}$ as persistent systolic arterial pressure $>150 \mathrm{~mm} \mathrm{Hg} \underset{\mathbb{D}}{ }$ or diastolic arterial pressure $>95 \mathrm{~mm} \mathrm{Hg}$ before $\stackrel{\varrho}{\circ}$ antihypertensive treatment was started or four weeks 
after the discontinuation of antihypertensive drugs. Essential hypertension was diagnosed in all 57 patients and all of them had echocardiographic evidence of left ventricular hypertrophy: (a) interventricular septal wall thickness of $\geqslant 12 \mathrm{~mm}$ at end diastole, $(b)$ left ventricular end diastolic posterior wall thickness of $\geqslant 12 \mathrm{~mm}$, and $(c)$ left ventricular mass greater than $2 \mathrm{SD}$ deviations above the normal mean. To restrict the study to patients with pure hypertrophy we studied only those with a left ventricular end diastolic diameter of $<55 \mathrm{~mm}$ (46 men and 11 women aged 43-68). None of these patients had evidence of other heart disease from their cardiovascular history, or from physical examination, electrocardiography, or echocardiography; and they were all in sinus rhythm without signs of heart failure. Because coronary arteriography was not justified in these patients concomitant coronary artery disease had to be excluded on clinical grounds alone. Thus the patients in this study had arterial hypertension without clinically evident coronary artery disease.

The patients consented to the following tests, which were performed before introduction of antihypertensive treatment or four weeks after its discontinuation. Eight (42\%) patients in group 1, 11 $(44 \%)$ patients in group $2 \mathrm{~A}$, and five $(38 \%)$ ) patients in group 2B had been treated with antihypertensive agents more than four weeks before the study. The duration of treatment was $4.8(1.5)$ years in group 1 , $3.7(2.7)$ years in group $2 \mathrm{~A}$, and $4.4(3.3)$ years in group 2B. In group 1 five (33\%) patients had been on a thiazide, five $(33 \%)$ on $\beta$ blockers, three $(17 \%)$ on methyldopa, two (11\%) on calcium antagonists, and one $(6 \%)$ on hydralazine; in group $2 \mathrm{~A}$ eight $(38 \%)$, seven $(33 \%)$, two $(10 \%)$, two $(10 \%)$, one $(5 \%)$ had been on the same drugs, and one $(5 \%$ ) had been on captopril; and in group 2B the corresponding figures were three $(38 \%)$, three $(38 \%)$, one $(13 \%)$, and $\alpha$ blocker in one $(13 \%)$. Thus there were no significant differences in the treatment before the tests among the groups.

\section{ESTIMATION OF LEFT VENTRICULAR STRUCTURE} AND FUNCTION

$M$ mode and cross sectional echocardiograms were obtained with a Toshiba SSH-11A cross sectional ultrasonoscope with a $2 \cdot 25 \mathrm{MHz}$ transducer. A cross sectional echocardiogram was recorded on a video system (Victor Umatic CR 6060) and $M$ mode echocardiograms were photographed on light sensitive paper (Kodak Linagraph, 1985) at a paper speed of $50 \mathrm{~mm} / \mathrm{s}$ using a Honeywell 1956 strip chart recorder. The echocardiograms were obtained during expiration. The measurements were performed by two observers (who were unaware of the patient's clinical state) from at least six consecutive cardiac cycles. The thickness of the interventricular septum and ventricular posterior wall was measured at the time of the $\mathbf{R}$ wave on the electrocardiogram (end diastole), with the ultrasonic beam directed just below the tip of the anterior mitral leaflet on $\mathrm{M}$ mode echocardiograms. The left ventricular diameter was measured as the distance between the echoes of the left ventricular posterior wall and of the interventricular septum, just below the tip of the mitral leaflets at the level of the chordae tendineae. The diameter of the left ventricle was measured at end diastole and end systole (when the endocardial surface of septum was closest to the posterior wall of the left ventricle). All measurements were made with a centimetre scale superimposed on the echocardiogram. Fractional shortening (an index of the ejection phase) was calculated as left ventricular end diastolic diameter minus left ventricular end systolic diameter divided by left ventricular end diastolic diameter, and the result was expressed as a percentage.

Left ventricular mass was calculated by a pathologically validated regression method: 1.04 (left ventricular end diastolic diameter + interventricular septal and posterior wall thicknesses) ${ }^{3}$ - left ventricular end diastolic diameter $\left.{ }^{3}\right)-14 .^{3}$

The end systolic wall stress was calculated by the equation: (peak arterial pressure) $\times$ (left ventricular end systolic diameter) $)^{2} / 4$ (left ventricular wall thickness) $\times$ (left ventricular end systolic diameter + wall thickness). ${ }^{4}$ This is an expression of the average meridional wall stress which may be defined as the force per unit area acting at the equatorial plane of the ventricle in the direction of the apex-to-base axis. The calculation of end systolic wall stress from these measures has been validated. ${ }^{56}$

Table 1 shows the normal values of haemodynamic variables obtained from 22 healthy subjects in our

Table 1 Data (mean (SD)) used to calculate left ventricular mass and end systolic stress in 22 healthy volunteers (mean (SD) age 46 (10) years, 17 men and 5 women) in whom physical and laboratory examinations did not show any abnormality

\begin{tabular}{lc}
\hline Variable & Value \\
\hline Heart rate (beats/min) & $70(8)$ \\
Systolic blood pressure (mm Hg) & $127(13)$ \\
Diastolic blood pressure (mm Hg) & $80(9)$ \\
Left ventricular end diastolic diameter $(\mathrm{mm})$ & $48(3)$ \\
Left ventricular end systolic diameter $(\mathrm{mm})$ & $30(3)$ \\
Fractional shortening (\%) & $37(5)$ \\
Interventricular septal wall thickness $(\mathrm{mm})$ & $9(1)$ \\
Left ventricular posterior wall thickness $(\mathrm{mm})$ & $10(1)$ \\
Left ventricular mass $(\mathrm{g})$ & $180(30)$ \\
Left ventricular end systolic stress $\left(\mathrm{g} / \mathrm{cm}^{2}\right)$ & $60 \cdot 8(12 \cdot 2)$ \\
Plasma noradrenaline $(\mathrm{pg} / \mathrm{ml})$ & $148(41)$ \\
\hline
\end{tabular}


laboratory. These are not significantly different from those of other investigators. ${ }^{34}$

The patients were separated into two groups: group 1 consisted of 19 patients with end systolic wall stress $<2$ SD below the normal mean $\left(<36.4 \mathrm{~g} / \mathrm{cm}^{2}\right)$ and group 2 consisted of 38 patients with end systolic wall stress within $2 \mathrm{SD}$ of the normal mean. (No patient in this study had end systolic wall stress more than 2 SD above the normal mean.) It has been reported that the mean left ventricular mass calculated echocardiographically in hypertensive patients with left ventricular hypertrophy is approximately twice the normal mean value. ${ }^{78}$ So we divided group 2 into two subgroups: group 2A consisted of 25 patients with calculated left ventricular mass of twice the normal mean or smaller $(\leqslant 360 \mathrm{~g}$ ) and group 2B consisted of 13 patients with left ventricular mass more than twice the normal mean $(>360 \mathrm{~g})$.

We studied the effect of isoproterenol by comparing the relation between fractional shortening and end systolic wall stress before and after isoproterenol. End systolic wall stress was reduced by isoproterenol. To increase the accuracy of the regression line of the relation between fractional shortening and end systolic wall stress before isoproterenol we increased the number of measurements for smaller end systolic wall stress before isoproterenol in 10 patients (five of group 1, four of group 2A, and one of group 2B) by slow infusion of a solution of sodium nitroprusside (25 $\mathrm{mg} / 500 \mathrm{ml}$ ). Left ventricular dimension and arterial pressure were recorded every $30 \mathrm{~s}$ during the infusion, until the peak arterial pressure decreased by $30 \%$ of the initial value or the heart rate increased by $10 \%$ of the initial value, because chronotropic change may influence the inotropic effect. ${ }^{4}$

\section{ADRENERGIC RESPONSES}

Plasma noradrenaline

Before the start of echocardiographic examination after isoproterenol infusion we collected venous blood samples to determine plasma noradrenaline. Samples were collected after the subject had rested supine for at least 20 minutes with an indwelling butterfly needle in an arm vein. Plasma was separated in a refrigerated centrifuge at $2^{\circ} \mathrm{C}$ and stored at $-40^{\circ} \mathrm{C}$. Noradrenaline was adsorbed on to activated alumina at $\mathrm{pH} 8.55$ by adding Tris- $\mathrm{HCl}$ buffer $(\mathrm{pH}$ $8 \cdot 55)$. Noradrenaline-adsorbed alumina was washed by water followed by elution with $100 \mu \mathrm{l}$ of $0.25 \mathrm{~mol} / \mathrm{l}$ acetic acid. After purification with alumina, noradrenaline was separated by high-performance liquid chromatography and was measured spectrofluorometrically by the trihydroxyindole method (Shimadzu spectrofluorometer RF-500 LCA). (Table 1 shows the normal value.)

\section{Isoproterenol echocardiography}

The study was performed in the afternoon in al patients. Simultaneous cross sectional and $M$ modeo echocardiographic and electrocardiographic baseline recordings and blood pressure measurements weres performed with the patient in a supine position immediately before intravenous infusion of isoproterenol $(0.02 \mu \mathrm{g} / \mathrm{kg} / \mathrm{min})$ via a calibrated infusion pump. After 5 minutes' infusion, cros $\overrightarrow{0}$ sectional and $M$ mode echocardiograms and an electrocardiogram were recorded and blood pressures was measured by cuff sphygmomanometer. The transducer was held at the same part on the chest walf throughout the examinations. To standardise the technique between patients, as well as in the samo patient before and after the infusion of isoproterenol $\vec{A}$ we tried to record the echocardiograms at the same part of the left ventricle (just below the tip of the anterior mitral leaflet) before and after the infusion of isoproterenol. The beams of $M$ mode echocardiogra $\frac{0}{7}$ phy were aligned perpendicularly with the posterion walls of the left ventricle and with the wall of the interventricular septum in all the patients both $\overrightarrow{0}$ before and after the infusion of isoproterenol.

STATISTICAL ANALYSIS

We used the $t$ test, paired $t$ test, correlation regression equations, $\mathrm{F}$ test, and one-way analysis on variance as appropriate. All results in which $p<0.05$ were regarded as statistically significant.

\section{Results}

HAEMODYNAMIC AND ECHOCARDIOGRAPHIC FINDINGS

Table 2 shows the values of haemodynamic, echocar diographic, and other variables before the infusion of isoproterenol. There were no significant differences in age, sex, and heart rate among the groups. Systoliç blood pressure was significantly lower in group $\vec{b}$ than in groups $2 \mathrm{~A}$ and $2 \mathrm{~B}$ ( $\mathrm{p}<0.01$ and $\mathrm{p}<0.00 \mathrm{P}$ respectively). Left ventricular end diastolic and en $\$$ systolic diameters were significantly smaller in group. 1 than in groups $2 A$ and $2 B(p<0.05$ and $p<0.05 \%$ $\mathrm{p}<0.001$ and $\mathrm{p}<0.001$ respectively). Fractional shortening was significantly larger in group 1 than in groups $2 A$ and $2 B(p<0.001$ and $p<0.001$ respec $\sigma$ tively), but there was no significant difference bet ween group 2A and group 2B. The interventriculat septum was significantly thicker in groups 1 and $2 \mathrm{~F}$ than in group $2 \mathrm{~A}(\mathrm{p}<0.001)$, but there was no significant difference in the thickness of the posterio. wall among the groups. There was asymmetric septa $\vec{P}$ hypertrophy (interventricular septal thickness: pos $\overrightarrow{\mathbb{D}}$ terior wall thickness $\geqslant 1.3)$ in seven $(37 \%)$ patients in group $1,2(8 \%)$ patients in group $2 \mathrm{~A}$, and five $(38 \%$ 
Table 2 Results (mean (2 SD)) of the study population at baseline

\begin{tabular}{|c|c|c|c|c|c|c|}
\hline \multirow[b]{2}{*}{ Variables } & \multicolumn{3}{|l|}{ Group } & \multicolumn{3}{|l|}{ pvalues } \\
\hline & 1 & $2 A$ & $2 B$ & 1 ขs $2 A$ & $2 A v s 2 B$ & 1 vs $2 B$ \\
\hline $\begin{array}{l}\text { No } \\
\text { Age (years) } \\
\text { Men/women } \\
\text { Heart rate (beats/min) } \\
\text { Systolic blood pressure (mm Hg) } \\
\text { Diastolic blood pressure }(\mathrm{mm} \mathrm{Hg}) \\
\text { Left ventricular end diastolic diameter }(\mathrm{mm}) \\
\text { Left ventricular end systolic diameter }(\mathrm{mm}) \\
\text { Fractional shortening }(\%) \\
\text { Interventricular septal thickness }(\mathrm{mm}) \\
\text { Left ventricular posterior wall thickness }(\mathrm{mm}) \\
\text { Left ventricular mass }(\mathrm{g}) \\
\text { Left ventricular end systolic wall stress }\left(\mathrm{g} / \mathrm{cm}^{2}\right) \\
\text { Plasma noradrenaline }(\mathrm{pg} / \mathrm{ml})\end{array}$ & $\begin{array}{l}19 \\
51 / 7 \\
16 / 3 \\
65(10) \\
151(13) \\
101(9) \\
44(4) \\
21(3) \\
52(4) \\
17(3) \\
14(2) \\
339(62) \\
25 \cdot 6(8 \cdot 5) \\
140(84)\end{array}$ & $\begin{array}{l}25 \\
47 / 7 \\
19 / 6 \\
69(11) \\
168(19) \\
109(12) \\
47(4) \\
29(4) \\
39(7) \\
14(2) \\
14(2) \\
307(39) \\
53.6(12.4) \\
159(75)\end{array}$ & $\begin{array}{l}13 \\
50 / 11 \\
11 / 1 \\
66(11) \\
172(15) \\
106(14) \\
47(3) \\
31(4) \\
34(7) \\
18(2) \\
15(2) \\
404(45) \\
55 \cdot 1(12 \cdot 7) \\
302(147)\end{array}$ & $\begin{array}{l}\text { NS } \\
\text { NS } \\
\text { NS } \\
<0.01 \\
<0.05 \\
<0.05 \\
<0.001 \\
<0.001 \\
<0.001 \\
\text { NS } \\
<0.05 \\
\overline{N S}\end{array}$ & $\begin{array}{l}\text { NS } \\
\text { NS } \\
\text { NS } \\
\text { NS } \\
\text { NS } \\
\text { NS } \\
\text { NS } \\
\text { NS } \\
<0.001 \\
\text { NS } \\
\text { NS } \\
<0.001\end{array}$ & $\begin{array}{l}\text { NS } \\
\text { NS } \\
\text { NS } \\
<0.001 \\
\text { NS } \\
<0.05 \\
<0.001 \\
<0.001 \\
\text { NS } \\
\text { NS } \\
<0.01 \\
- \\
<0.001\end{array}$ \\
\hline
\end{tabular}

patients in group 2B. There was also hypertrophy in the apical region of the left ventricle in four patients in group 1 and two in group 2B. No patient had systolic anterior motion of the mitral valve. Left ventricular mass was significantly larger in group 1 than in group $2 \mathrm{~A}(\mathrm{p}<0.05)$ and was significantly larger in group $2 B$ than in group $1(p<0.01)$. There was no significant difference in end systolic wall stress between groups $2 \mathrm{~A}$ and $2 \mathrm{~B}$.

During the infusion of sodium nitroprusside, two to five measurements were obtained in each patient before the end point-that is when the peak arterial pressure had decreased by $30 \%$ of the initial value or the heart rate had increased by $10 \%$ of the initial value. At the end point, end systolic wall stress had fallen from $39.3(11.9)$ to $27.8(10.0) \mathrm{g} / \mathrm{cm}^{2}$ with an increase of fractional shortening from $46(5)$ to $49(5)$.

Figure 1 shows the relation between fractional shortening and end systolic wall stress for 57 measurements obtained before the infusion of isoproterenol in all the patients and 35 measurements obtained during the infusion of sodium nitroprusside. There was a statistically significant inverse linear relation between fractional shortening and end systolic wall stress (slope $-0.448, r=0.879$, $\mathrm{p}<001, \alpha<0.005)$ when the end systolic wall stress was $12 \mathrm{~g} / \mathrm{cm}^{2}$.

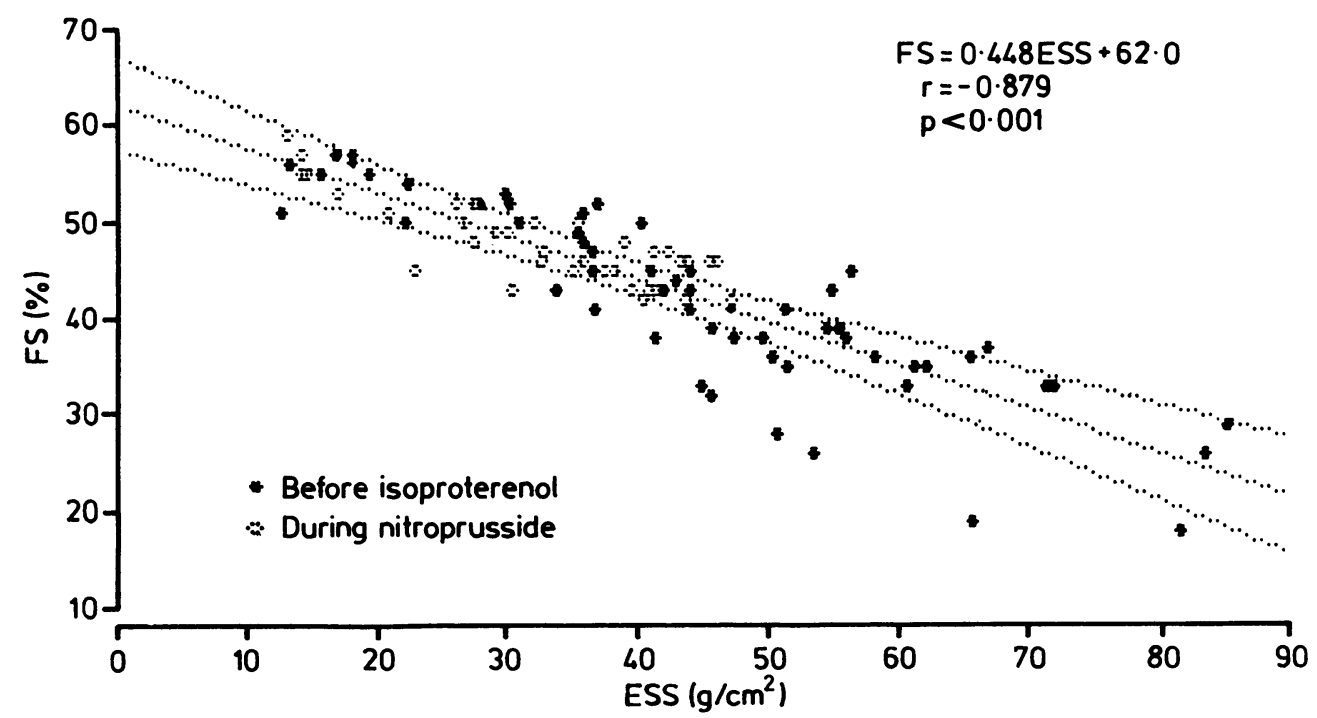

Fig 1 Relation between left ventricular end systolic wall stress (ESS) and fractional shortening (FS) before and during the infusion of isoproterenol. There was a significantly negative linear relation when $E S S$ was $>12 \mathrm{~g} / \mathrm{cm}^{2}$. The broken lines show the regression line and the confidence interval. 


\section{ADRENERGIC RESPONSES}

\section{Plasma noradrenaline}

The concentration of plasma noradrenaline was significantly higher in group $2 \mathrm{~B}$ than in groups 1 and $2 A$ ( $p<0.001$ respectively) (table 2 ).

Effect of isoproterenol on echocardiographic variables Figure 2 shows echocardiograms obtained before and after the infusion of isoproterenol in a 47 year old man. The echoes of the left side of the interventricular septum and of the endocardium of the left ventricular posterior wall can be seen clearly in both of the echocardiograms. The presence of echoes from the chordae tendineae indicates that both these echocardiograms are from the same part of the left ventricle. Infusion of isoproterenol caused hyperkinesis. Clear echocardiograms were obtained from the same part of the left ventricle before and after the infusion of isoproterenol in all but five patients (one in group 1 , two in group $2 \mathrm{~A}$, and two in group $2 \mathrm{~B}$ ). In three patients in group 1 , end systolic wall stress decreased to below $12 \mathrm{~g} / \mathrm{m}^{2}$. These three patients were excluded from the analysis of the effect of isoproterenol because the linear relation between fractional shortening and end systolic wall stress operated only when end systolic wall stress was $>12$ $\mathrm{g} / \mathrm{cm}^{2}$ (figure 1 ).

Infusion of isoproterenol increased the mean (SD) heart rate from 66 (9) to 97 (17) beats/min +32 (11) in group 1, from 70 (11) to $101(13)+32$ (8) in group $2 \mathrm{~A}$, and from $65(11)$ to $96(19)+31$ (12) in group $2 \mathrm{~B}$. There were no significant differences among the groups. Systolic blood pressure changed (but not significantly) from 151 (9) to 160 (15) $\mathrm{mm} \mathrm{Hg}$ in group 1, from 169 (19) to $180(22) \mathrm{mm} \mathrm{Hg}$ in group $2 \mathrm{~A}$, and from 171 (15) to $165(28) \mathrm{mm} \mathrm{Hg}$ in group 2B. Diastolic blood pressure decreased from 100 (9) to 90 (14) $\mathrm{mm} \mathrm{Hg}$ in group 1 , from $110(12)$ to $95(13)^{2}$ $\mathrm{mm} \mathrm{Hg}$ in group $2 \mathrm{~A}$, and from 103 (13) to 83 (14) $\mathrm{mmo}$ $\mathrm{Hg}$ in group $2 \mathrm{~B}(\mathrm{p}<0.001$ in each group). Lef ventricular end diastolic diameter did not change significantly (44 (4) to 44 (3) $\mathrm{mm}$ in group 1,47 (4) to 46 (4) $\mathrm{mm}$ in group $2 \mathrm{~A}$, and 47 (4) to 46 (4) $\mathrm{mm}$ in? group 2B). Left ventricular end systolic diameten decreased from 21 (3) to 17 (2) $\mathrm{mm}$ in group 1, from 29 (4) to 23 (4) $\mathrm{mm}$ in group $2 \mathrm{~A}$, and from 31 (3) to 25 (4) $\mathrm{mm}$ in group $2 B(p<0.001$ in each group).

Fractional shortening increased from 52 (4) to 62 (4) \% in group 1 , from $39(7)$ to $50(9) \%$ in group $2 \mathrm{~A}$. and from 34 (6) to $45(6) \%$ in group $2 B$ (p $<0.001$ in each group). End systolic wall stress decreased from $26.2(7.6)$ to $17.2(5.5) \mathrm{g} / \mathrm{cm}^{2}$ in group 1 , from 53.3. (12.1) to $37 \cdot 3(14 \cdot 1) \mathrm{g} / \mathrm{cm}^{2}$ in group $2 \mathrm{~A}$, and from $53 . \mathrm{c}^{2}$ $(10.6)$ to $33.0(10.4) \mathrm{g} / \mathrm{cm}^{2}$ in group $2 B$. Figure $\frac{3}{s}$. shows the changes of the relation between fractiona? shortening and end systolic wall stress in each group. It suggests that there was a different slope for each of the groups. Figure 4 shows the increase of fractional shortening corrected for the decrease of end systolie. wall stress, that is the slope of the change of the relation between fractional shortening and end sys $\bar{\pi}_{\bar{\pi}}$ tolic wall stress. This variable ( $\triangle$ fractionaP shortening / $-\triangle$ end systolic wall stress) shows the response of myocardial contractility to isoproterenof because the changes in this variable are within the range in which fractional shortening and end systoli wall stress are linearly related in fig 1 . The increase in fractional shortening was significantly larger in group $1\left(1.40(0.60) \mathrm{cm}^{2} / \mathrm{g}\right)$ than in group $2 \mathrm{~A}(0.8 .50$ $\left.(0.39) \mathrm{cm}^{2} / \mathrm{g}\right)(\mathrm{p}<0.05)$ and was significantly largef in group $2 \mathrm{~A}$ than in group $2 \mathrm{~B}\left(0.56(0.15) \mathrm{cm}^{2} / \mathrm{g}\right.$ 解 $(\mathrm{p}<0.05)$. 

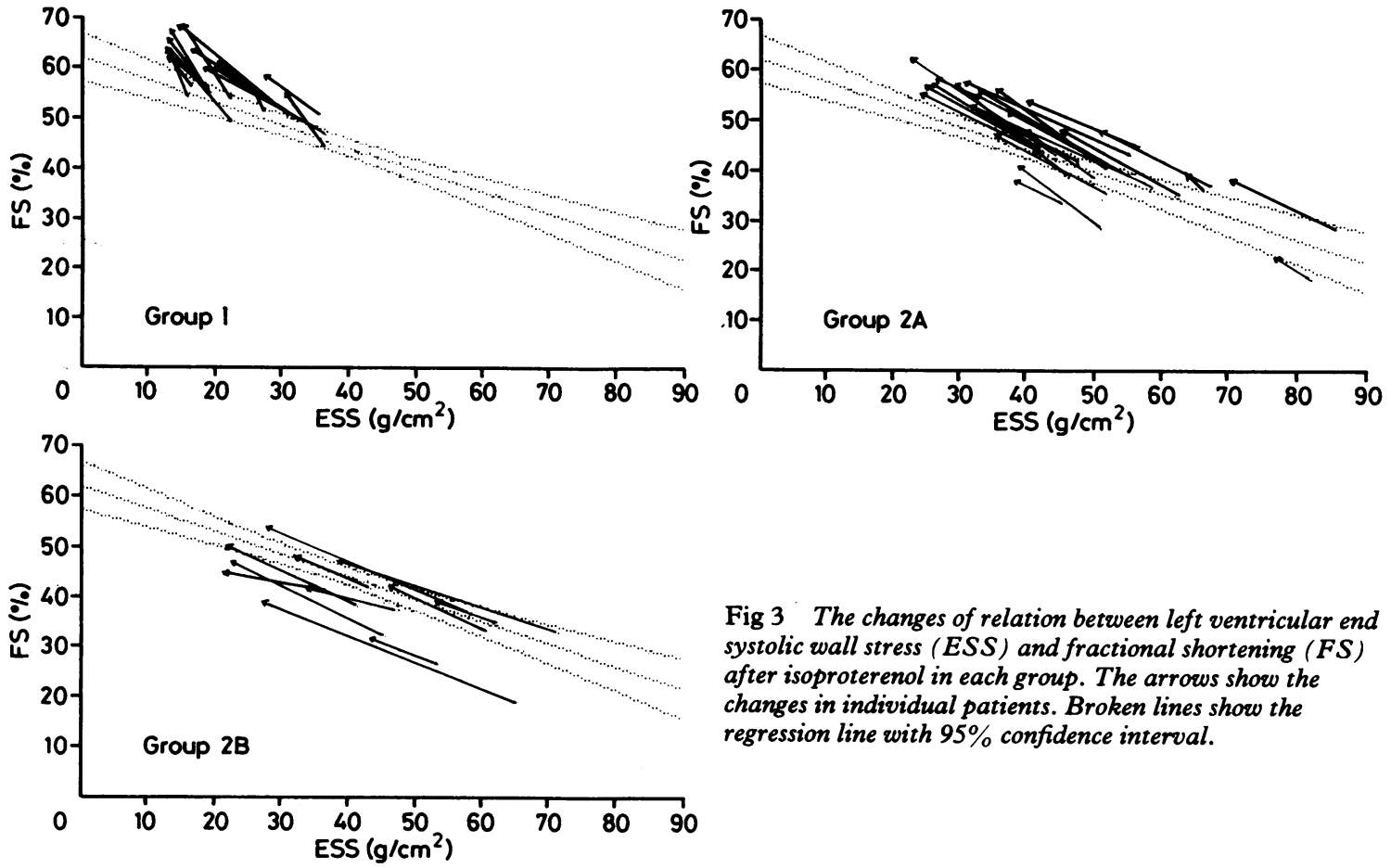

Fig 3 The changes of relation between left ventricular end systolic wall stress (ESS) and fractional shortening (FS) after isoproterenol in each group. The arrows show the changes in individual patients. Broken lines show the regression line with $95 \%$ confidence interval.

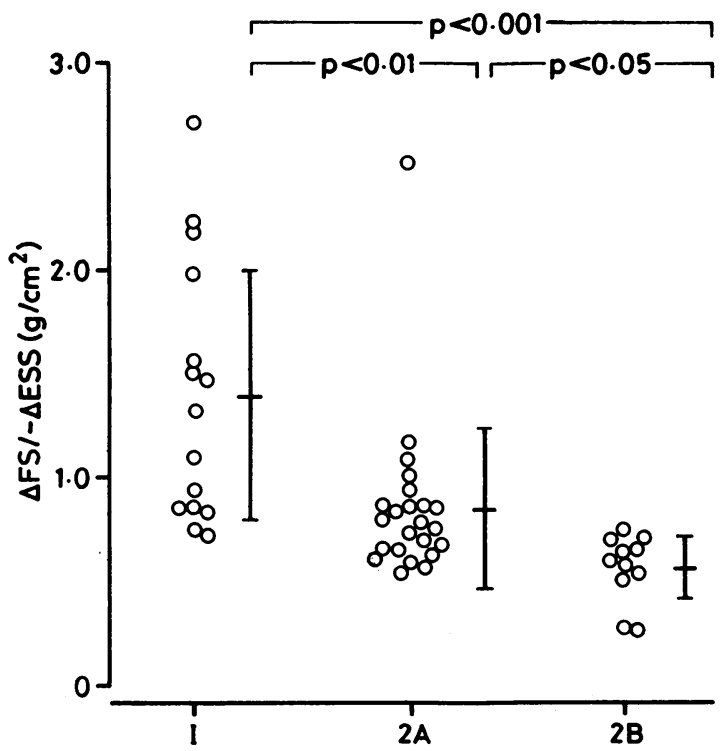

Fig 4 The increase of fractional shortening produced by infusion of isoproterenol ( $\triangle F S$ ) after correction for the decrease of left ventricular end systolic wall stress ( $\triangle E S S$ ) $(\Delta F S /-\Delta E S S)$.

\section{Discussion}

ECHOCARDIOGRAPHIC STUDY OF MYOCARDIAL MECHANICS

Echocardiographic measurements of left ventricular dimensions are known to be reliable. ${ }^{910}$ Changes of less than $2 \mathrm{~mm}$ in the echocardiogram do not represent clinically significant changes. In the present study, we used the echocardiographic method to calculate left ventricular mass and wall stress, as have others. ${ }^{49}$ Even small measurement errors in wall thickness may significantly influence left ventricular mass and wall stress; however, the values we obtained in the present study resembled those obtained by others. ${ }^{49}$ The reported relative errors of fractional shortening and end systolic wall stress are about $0.4 \%$ and $25 \%$ respectively. ${ }^{11}$ So the differences in $\Delta$ fractional shortening $/-\Delta$ end systolic wall stress that we found among our study groups are likely to be real because they were all more than $26 \%$.

\section{CARDIAC HYPERTROPHY}

Chronic pressure overloading of the heart is believed to lead to wall thickening that is commensurate with the increased systolic pressure and tends to normalise 
myocardial wall stress ${ }^{1213}$ (appropriate hypertrophy). In hypertrophic cardiomyopathy, however, there is inappropriate hypertrophy in response to pressure overload. ${ }^{14}$ Such hypertrophy must be caused by factors other than mechanical overload.

\section{LEFT VENTRICULAR EJECTION PHASE INDICES AND WALL STRESS}

An immense linear correlation was found between fractional shortening and ejection fraction and left ventricular wall stress in normal controls, ${ }^{15}$ in hypertension, ${ }^{9}$ and in other heart diseases. ${ }^{16}{ }^{17}$ An inverse curvilinear correlation has also been reported between the velocity of left ventricular fibre shortening and left ventricular wall stress. ${ }^{16}$ In our study we used $\Delta$ fractional shortening / $-\Delta$ end systolic wall stress as an index of the response of myocardial contractility in the range in which fractional shortening and end systolic wall stress were considered to be related linearly in fig 1 .

To exclude the possibility that $\triangle$ fractional shortening $/-\Delta$ end systolic wall stress might have been larger in the cases with a smaller end systolic wall stress, we performed isoproterenol echocardiography in three patients who had left ventricular hypertrophy but no aortic pressure gradient because they had had a valve replacement for aortic stenosis (table 3). They had small end systolic wall stress with a small value for $\Delta$ fractional shortening $/-\Delta$ end systolic wall stress. This indicates that $\triangle$ fractional shortening $/-\triangle$ end systolic wall stress is a valid index of the response of myocardial contractility; the number of the cases is small, however.

The relation between indices of left ventricular ejection and afterload may also be influenced by a

Table 3 Results (mean (SD)) of isoproterenol echocardiography in three patients with left ventricular hypertrophy who had had valve replacement for aortic stenosis and had no aortic pressure gradient

\begin{tabular}{|c|c|c|}
\hline Variable & Baseline & Isoproterenol \\
\hline $\begin{array}{l}\text { Age (yr) } \\
\text { Sex (M/F) } \\
\text { Heart rate } \\
\text { Systolic blood pressure (mm Hg) } \\
\text { Diastolic blood pressure (mm Hg) } \\
\text { Left ventricular end diastolic } \\
\text { diameter (mm) } \\
\text { Left ventricular end systolic } \\
\quad \text { diameter (mm) } \\
\text { Fractional shortening (\%) } \\
\text { Interventricular septal wall } \\
\text { thickness (mm) } \\
\text { Left ventricular posterior wall } \\
\text { thickness (mm) } \\
\text { Left ventricular mass }(\mathrm{g}) \\
\text { Left ventricular end systolic } \\
\text { stress (g/cm }{ }^{2} \text { ) } \\
\Delta \text { fractional shortening/ }-\triangle \text { end } \\
\text { systolic wall stress }\left(\mathrm{cm}^{2} / \mathrm{g}\right)\end{array}$ & $\begin{array}{c}56(2) \\
2: 1 \\
68(14) \\
128(19) \\
75(10) \\
41(1) \\
23(4) \\
43(8) \\
17(2) \\
18(1) \\
381(71) \\
26 \cdot 7(9 \cdot 1)\end{array}$ & $\begin{array}{c}105(33) \\
119(17) \\
63(17) \\
\\
40(2) \\
21(4) \\
47(7)\end{array}$ \\
\hline
\end{tabular}

change of preload; however, this effect can be ignored: in this study because the left ventricular end diastolic diameter did not change with isoproterenol infusiono in any of the groups.

\section{ADRENERGIC RESPONSE IN HYPERTENSIVE} HYPERTROPHY

It has been suggested that, as well as mechanical ${ }^{\infty}$ factors, neurohormonal influences could have an important role in the cardiac hypertrophy of $\vec{\omega}$ hypertension..$^{18}$ Small doses of isoproterenol or othero catecholamines produced hypertrophy in laboratory animals without changing blood pressure and heartir rate. ${ }^{1920}$

The aetiology of hypertrophic cardiomyopathy isi not yet known. A disorder of catecholamine function + has been suggested, ${ }^{21}$ and hypersensitivity of the의 $\beta$ adrenergic receptor system has been proposed to explain hypertrophic cardiomyopathy with asymmetric septal hypertrophy. ${ }^{22}$

Whether the presence of asymmetric septal hyper-âे trophy in hypertensive patients is the result of $\mathrm{a}^{2}$ strong response to an increased afterload or is $a \overrightarrow{0}$ coincidental occurrence is not clear. In our study, $y_{2}^{\infty}$ asymmetric septal hypertrophy was more common in groups 1 and $2 B$ than in group $2 A$. It may be that the mechanisms of asymmetric septal hypertrophy differed in groups 1 and 2B. The adrenergic response in group 1 resembled that found in hypertrophic cardiomyopathy, whereas that in group $2 \mathrm{~B}$ resembled the response to high arterial pressure.

In patients in group 1 end systolic wall stress was less than normal, and these patients were moreo responsive to isoproterenol than those with the other types of hypertensive hypertrophy. Hypertrophy in group 1 may be the result of a combination of the? hypertension and a factor causing hypertrophic cardiomyopathy; this second factor will be difficult to identify since in hypertrophic cardiomyopathy, by을 definition, there is no cause established. Alternatively, patients in group 1 may have had an early stage of hypertension; this is not likely, however, as these patients were not young and they had had․ hypertension for at least five years.

Group 2B (severe hypertrophy) was significantly less responsive to isoproterenol than group $2 \mathrm{~A}$ (mild hypertrophy) ( $p<0.01$ ). This clinical result may support the experimental results of others. ${ }^{23}$ The blunting of inotropic responsiveness to $\beta$ adrenergice stimulation may be one of the mechanisms causinge progression from left ventricular hypertrophy to heart failure in hypertensive disease.

The degree of left ventricular hypertrophy hasi been reported to be positively related to circulating concentrations of plasma noradrenaline. ${ }^{24}$ But this relation is still controversial. In our study, increasedK 
concentrations of plasma noradrenaline were found only in group 2B. Patients in group 1 had normal plasma noradrenaline. Perhaps the increase in plasma noradrenaline in hypertensive hypertrophy is a secondary phenomenon. A depressed $\beta$ adrenergic reserve might prompt a compensatory increase in plasma noradrenaline.

\section{CLINICAL IMPLICATIONS}

Our study showed that inotropic responsiveness to isoproterenol infusion was higher in hearts with lower than normal values for end systolic wall stress than hearts with other types of hypertensive hypertrophy, although hypertrophy in the former group was not mild. On the other hand, patients with normal end systolic wall stress and severe hypertrophy were less responsive to $\beta$ adrenergic stimulation than those with the other hypertensive hypertrophy. The inotropic responsiveness to isoproterenol might be regulated by the conditions of $\beta$ adrenergic receptors in the myocardium when myocardial contractility is normal. Myocardial contractility did not appear to differ among the three groups-groups 1 and 2 seemed to be on the same regression line in fig 1 . Groups $2 \mathrm{~A}$ and $2 \mathrm{~B}$ did not show significantly different fractional shortening and end systolic wall stress.

In hypertensive patients with subnormal end systolic wall stress and increased responsiveness to isoproterenol, cardiac hypertrophy (inappropriate hypertrophy) may have been induced by a nonmechanical (probably neurohormonal) factor; but in those with normal end systolic wall stress the cardiac hypertrophy (appropriate hypertrophy) might have been induced by a mechanical factor (for example high arterial pressure) and might progress to left ventricular dysfunction with impairment of $\beta$ adrenergic reserve and increased plasma noradrenaline. Thus classification of hypertensive hypertrophy according to the contribution made by a mechanical factor (left ventricular systolic wall stress) and a non-mechanical factor ( $\beta$ adrenergic response) may be useful in identifying the aetiology and pathophysiology in individual patients.

This work was supported by grants from the Japanese Ministry of Health and Welfare for the study of idiopathic cardiomyopathy.

\section{References}

1 Fernandes M, Onesti G, Fiorentini R, Kim KE, Swartz C. Effects of chronic administration of propranolol on the blood pressure and heart weight in experimental renal hypertension. Life Sci 1976;18:967-70.

2 Pagano VT, Inechiosa MA. Cardiomegaly produced by chronic beta adrenergic stimulation in the rat. Com- parison in alpha adrenergic effects. Life Sci 1977;21:619-24.

3 Devereux RB, Reichek N. Echocardiographic determination of left ventricular mass in man: anatomic validation of the method. Circulation 1977;55:613-8.

4 Takahashi H, Sasayama S, Kawai C, Kotoura H. Contractile performance of the hypertrophied ventricle in patients with systemic hypertension.Circulation 1980;62:116-26.

5 Reichek N, Wilson J, Sutton MSJ, Plappert TA, Goldberg S, Hirschfeld JW. Noninvasive determination of left ventricular end-systolic stress: validation of the method and initial application. Circulation 1982;65:99-108.

6 Greenberg B, Massie B, Thomas D, et al. Association between the exercise ejection fraction response and systolic wall stress in patients with chronic aortic regurgitation. Circulation 1985;71:458-65.

7 Nichols AB, Scicca RR, Weiss MB, Blood DIC, Brennan DL, Cannon PJ. Effect of left ventricular hypertrophy on myocardial blood flow and ventricular performance in systemic hypertension. Circulation 1980;62:329-40.

8 Dreslinski GR, Frohlich ED, Dunn FG, Messeri FH, Suarez DH, Reisin E. Echocardiographic diastolic ventricular abnormality in hypertensive heart disease: atrial emptying index. Am J Cardiol 1981;47:108790.

9 Nakashima Y, Fouad FM, Tarazi RC. Regression of left ventricular hypertrophy from systemic hypertension by enalapril. Am J Cardiol 1984;53:1044-9.

10 Reichek N, Devereux RB. Left ventricular hypertrophy; reliability of anatomic, echocardiographic and electrocardiographic findings. Circulation 1981;63:1391-8.

11 Sugishita Y, Matsuda M, Ito I, Koseki S. Evaluation of left ventricular reserve in left ventricular disease; non-invasive analysis of its determinants by dynamic exercise echocardiography. Acta Cardiol 1983;38: 103-13.

12 Hood VP, Ruckley CE, Rolett E. Wall stress in the normal and hypertrophied left ventricle. $A m J$ Cardiol 1968;22:550-8.

13 Grossman W, Jones D, McLaurin LP. Wall stress and patterns of hypertrophy in the human left ventricle. $J$ Clin Invest 1975;56:56-64.

14 Sugishita Y, Koseki S, Matsuda M, Yamaguchi T, Ito I. Myocardial mechanics of athletic heart in comparison with diseased hearts. Am Heart $J$ 1983;105:273-80.

15 Bonow KM, Green LH, Grossman W, Braunwald E. Left ventricular end-systolic stress-shortening and stress-length relation in humans: normal value and sensitivity to inotropic state. $\mathrm{Am} J$ Cardiol 1982;50:1301-8.

16 Gunther S, Grossman W. Determinations of ventricular function in pressure-overload hypertrophy in man. Circulation 1979;59:679-88.

17 Strauer BE. Left ventricular dynamics, energetics and coronary hemodynamics in hypertrophic heart disease. Eur Heart J 1983; 4:(suppl A):137-42.

18 Sen S, Tarazi RC, Khairallah PA, Bumpus FM. Cardiac hypertrophy in spontaneous hypertensive 
rats. Circ Res 1974;35:775-81.

19 Alderman EL, Emson DC. Myocardial hypertrophy resulting from low dosage isoproterenol administration in rats. Proc Soc Exp Biol Med 1971;136:268-70.

20 Laks $M H$, Morady F, Swart HJC. Myocardial hypertrophy produced by chronic infusion of subhypertensive doses of norepinephrine in the dog. Chest 1973;64:75-8.

21 Goodwin JF. Mechanisms in cardiomyopathies. $J \mathrm{Mol}$ Cell Cardiol 1985;17(suppl 2):5-9.

22 Iida $\mathrm{K}$, Sugishita $\mathrm{Y}$, Matsuda M, et al. Difference in response to isoproterenol between asymmetric septaf. hypertrophy and symmetric hypertrophy in patients with hypertrophic cardiomyopathy. Clin Cardiof 1986;9:7-12.

23 Ayobe $\mathrm{MH}$, Tarazi RC. Beta receptors and contractile reserve in left ventricular hypertrophy. Hypertensioff 1983;5(suppl I):I-192-7.

24 Corea L, Bentivoglio M, Verdecchia P, Motolese $M_{0}$ Plasma norepinephrine and left ventricular hyper $\stackrel{\oplus}{-}$ trophy in systemic hypertension. $A m J$ Cardio $\vec{\varnothing}$ 1984;53:1299-303. 